\title{
AN ASSESSMENT OF METHODS FOR SAMPLING CARABID BEETLES (COLEPTERA: CARABIDAE) IN A MONTANE RAIN FOREST
}

\author{
BA Nyundo and JG Yarro \\ University of Dar es Salaam, Department of Zoology \& Wildlife Conservation, P.O. Box 35064, \\ DAR ES SALAAM. E-mail: Bnyundo@uccmail.co.tz. \\ Telephone: 0748415981.
}

\begin{abstract}
Pitfall trapping is the traditional method for sampling carabid beetles and other grounddwelling invertebrates. Tests were carried out in the Udzungwa Mountains National Park between March 1999 and July 2000. Results indicated that pitfall traps were less efficient compared to manual searching methods, both in terms of relative abundance and species richness of carabid beetles. The results are discussed in the context of biodiversity inventories in the Eastern Arc Mountains.
\end{abstract}

\section{INTRODUCTION}

Pitfall traps are the traditional method for collection of epigaeic (ground-dwelling) invertebrates (Southwood and Henderson, 2000). It has been widely used for sampling carabid beetles in biodiversity inventories (Niemela et al. 1994, Davies 2000, Nyundo 2002), population and community ecology (Greenslade 1968, Refseth, 1980, Niemela1988, Niemela et al. 1989), and in studies dealing with the problem of sampling (Clark et al. 1995, Bremen and Terlutter 1994, Spence and Niemela 1994, Vennila and Rajagopal 1999). The reason for the wide use of pitfall traps in invertebrate sampling is their simplicity of setting and using, and their low cost in terms of manpower. Despite their usefulness, the interpretation of pitfall trap data is subject to many problems because they rarely reflect the true abundance of the target organisms being sampled. This is because there are numerous factors that influence the efficiency of the traps, including the materials from which the trap is made, the size and shape of the trap, the design, the attractant or preservative used in the trap and attributes of the target organism such as its size and foraging behaviour (Adis 1979). Despite these shortcomings pitfall traps have continued to be used. The biodiversity crisis facing tropical habitats make quick inexpensive collecting methods necessary for species inventorying.

Many studies have been carried out to compare various designs and approaches to pitfall trapping in order to obtain an optimum type of pitfall trap for specific objectives but only a few of these studies have been concerned with evaluating pitfall traps against non-pitfall methods (Spence and Niemela 1994, Zilihona and Nummelin 1999). In the present work the efficiency of pitfall traps in sampling carabid beetles is assessed by comparing them against ground searching methods.

\section{METHODS}

\section{Study area}

The inventory took place in three one-hectare plots in Mwanihana Forest, within the Udzungwa Mountains National Park. The plots were located at $500 \mathrm{~m}, 1000 \mathrm{~m}$ and $1500 \mathrm{~m}$ above sea level (Co-ordinates E36 ${ }^{\circ}$ $52^{\prime} 30^{\prime \prime} \mathrm{S}^{\circ} 50^{\prime} 50^{\prime \prime}, \mathrm{S} 36^{\circ} 52^{\prime} 50^{\prime \prime} 7^{\circ} 45^{\prime} 45^{\prime \prime}$, and $\mathrm{S} 36^{\circ} 52^{\prime} 30^{\prime \prime} \mathrm{E}^{\circ} 45^{\prime} 30^{\prime \prime}$ respectively).

Each plot was chosen such that it covered an area with more or less uniform forest, avoiding gaps, streams, rock faces and other breaks in the landscape. This was done to avoid sampling from different communities, which would confound the estimation of local species richness. 


\section{Collecting methods}

Carabid beetles were collected using two methods:

Pitfall trapping (PT): This involved using Plastic containers $(8 \mathrm{~cm}$ top width, $10 \mathrm{~cm}$ depth) sunken in the ground and half-filled with preservative liquid (formaldehyde). A total of 60 pitfall traps were set at each site, around each of the one-hectare plots. The traps were arranged in square grids with $20 \mathrm{~m}$ between traps to avoid the "digging in" effect. Opaque plastic lids were fixed above the traps to keep out rainwater and to stop birds and small animals from feeding on the insects. Trapping days were used as the measure of sampling effort in case of pitfall traps, each "sample" containing carabid beetles caught in one pitfall trap during 14 days of continuous trapping.

Hand searching on the ground (GS): Hand collecting was carried out by one of the authors (BN) and two field assistants, after instructions in the field on how to recognize carabid beetles and to use simple collecting methods. Collecting involved actively searching for the beetles on the ground, in leaf litter, under logs and other substrates, under tree barks, and in rotting deadwood. A $0.5 \mathrm{~cm}$ mesh size sifter was used to sift dry leaf litter for carabid beetles. Moist leaf litter was scooped onto white clothing (1 square metre beating sheet) and carabid beetles caught using a "pootah" (aspirator) or a pair of forceps. Resting beetles were sampled by manual searching under logs, stones and tree barks. Sampling effort was measured by time, each "sample" containing carabid beetles collected during one hour of continuous sampling. Collecting took place both during the day and at night.

The specimens were transferred directly into a killing agent cum preservative (9.0:0.5:0.5 parts of $70 \%$ ethyl alcohol, table vinegar and ethyl acetate by volume). Samples were collected during the rain season (March to May 1999, and May to June, 2000), and the dry season (August to October 1999 and September 2000).

\section{Statistical analysis and evaluation of the protocol}

Complementality

Species complementality (distinctness) was calculated to evaluate the difference (or otherwise) in the variety of carabid beetles collected by the three collectors. For every pair $\mathrm{j}$ and $\mathrm{k}$, the number of species in each group $\left(S_{j}\right.$ and $\left.S_{k}\right)$, and the number of species in common $\left(\mathrm{V}_{\mathrm{jk}}\right)$ were determined. Complementarity was given by the formula (Colwell and Coddington, 1994):

$$
C_{j k}=\frac{\left(S_{j}+S_{k}-2 V_{j k}\right)}{\left(S_{j}+S_{k}-V_{j k}\right)}
$$

Completeness of sampling

Completeness of sampling was assessed using the ratio of total number of individuals (specimens) to the total number of species. This is the sampling intensity of Coddington et al. (1991).

\section{Effect of collecting methods}

Mann-Whitney test was used to assess variation in specimens per sample between pairs of methods. To test the hypothesis that pitfall traps collect the same number of species as ground sampling methods chisquare test was used.

\section{RESULTS}

Six replicates were collected during the study yielding a combined total of 3097 ground beetles. The number of samples, total number of individual carabid beetles, total number of species and species complementality for the six replicates are shown in Table 1. The total number of individuals caught using the two methods was 3025 for ground-searching methods (mean of 4.97 individuals per one-hour sample) and 72 individuals for pitfall traps (mean of 0.20 individuals per trap for seven days or 0.03 individuals per trapping day). 
Table 1: Summary of carabid beetles collected from the UMNP using two methods

\begin{tabular}{llccccccc}
\hline Replicate & & 1 & 2 & 3 & 4 & 5 & 6 & TOTAL \\
\hline Method & & & & & & & & \\
\hline \multirow{2}{*}{ Ground } & Samples & 132 & 91 & 72 & 113 & 87 & 114 & 609 \\
searching & Total individuals & 251 & 820 & 100 & 146 & 475 & 1233 & 3025 \\
& Total species & 21 & 23 & 9 & 12 & 17 & 15 & \\
\hline \multirow{2}{*}{ Pitfall } & Samples & 60 & 60 & 60 & 60 & 60 & 60 & 360 \\
traps & Total individuals & 22 & 1 & 0 & 0 & 27 & 22 & 72 \\
& Total species & 9 & 1 & 0 & 0 & 6 & 4 & \\
\hline \multirow{2}{*}{ Complementality } & 0.846 & 0.957 & 1 & 1 & 0.722 & 0.882 & \\
\hline
\end{tabular}

There was a significant difference in the number of carabid beetles caught using ground searching and pitfall traps in all three replicates which had statistically meaningful data (Mann-Whitney $\mathrm{U}=6354.000,4774.000$ and 6700.000 at $500 \mathrm{~m}$ rainy season, $1500 \mathrm{~m}$ rainy season and $1500 \mathrm{~m}$ dry season respectively; $\quad \mathrm{p}=0.000)$. Species complementarity was high in all six replicates (Table 1). Chi-square analysis showed that pitfall traps collected significantly lower numbers of species compared to ground searching methods $\left(\chi^{2}=64.085, \mathrm{p}<0.05\right)$.

Completeness of sampling as measured by sampling intensity was high for ground searching compared to pitfall traps. In the former method it ranged from 11.11 to 82.20 , while in the latter it ranged from 0 to 5.55 (Table 2).

Table 2: Index of completeness of sampling (sampling intensity) in the two methods

\begin{tabular}{llcccccc}
\hline Replicate & & 1 & 2 & 3 & 4 & 5 & 6 \\
\hline Method & & & & & & & \\
\hline Ground & Total individuals (A) & 251 & 820 & 100 & 146 & 475 & 1233 \\
searching & Total species (B) & 21 & 23 & 9 & 12 & 17 & 15 \\
& Intensity of sampling (A/B) & $\mathbf{1 1 . 9 5}$ & $\mathbf{3 5 . 6 5}$ & $\mathbf{1 1 . 1 1}$ & $\mathbf{1 2 . 1 7}$ & $\mathbf{2 7 . 9 4}$ & $\mathbf{8 2 . 2 0}$ \\
\hline \multirow{2}{*}{ Pitfall } & Total individuals (A) & 22 & 1 & 0 & 0 & 27 & 22 \\
traps & Total species (B) & 9 & 1 & 0 & 0 & 6 & 4 \\
& Intensity of sampling (A/B) & $\mathbf{2 . 4 4}$ & $\mathbf{1}$ & $\mathbf{0}$ & $\mathbf{0}$ & $\mathbf{4 . 5 0}$ & $\mathbf{5 . 5 5}$ \\
\hline
\end{tabular}

\section{DISCUSSION}

There was a significant difference in the number of individuals and the number of species collected by the two methods in all six replicates. In all cases ground searching collected more individuals and more species of carabid beetles than pitfall traps.

The reasons for the low number of specimens per sample in pitfall traps is not easy to explain. This kind of trap (also 
known as Barber trap) is the traditional method for collecting carabid beetles. The traps are supposed to be quick to set and easy to service, at low cost since they do not need constant attention. All the above proved to be untrue in the Udzungwa mountains. The terrain is rugged, with steep slopes, stones, and a high density of tree roots, with heavy forest vegetation and a dense leaf litter in some places. During the rain season, and often during the "dry" season too, there are heavy downpours, making it necessary to empty the traps often to avoid flooding. Small mammals and birds raid the traps (again making it necessary to service the traps often). All these reasons make the setting of pitfall traps difficult. The same reasons probably explain why the catch was so low. Another possible reason for the poor performance of pitfall traps may be due to the behaviour of the beetles being sampled. High altitude carabid beetles are significantly smaller in size compared to savanna species. Due to their small size they tend to have different hunting behaviour, ambushing their prey or feeding on slow-moving prey (larvae of insects, snails and slugs) instead of running down the prey, as do lowland species. For example, at $500 \mathrm{~m}$ above sea level Pseudomegalonychus sp.nov. was the most abundant species during the wet season. 96 specimens of this species were collected, none of them from pitfall traps. The species are medium-sized (average of $6 \mathrm{~mm}$ in length), and their biology is unknown. Egadroma sp.1, the abundant species during the dry season, is also medium sized (average length $9 \mathrm{~mm}$ ). Members of this species are seed-feeders. Of the 538 individuals caught none came from pitfall trapping. The same phenomenon is repeated at $1500 \mathrm{~m}$ above sea level, where Tachyphanes sp., the most abundant species with 1168 individuals was not represented in pitfall trap samples. In contrast, large sized, night hunting species were well represented in pitfall trap samples. Examples are Galeritiola procera ssp. procera at $500 \mathrm{~m}$ above sea level and Metagonum sp. nov. at $1500 \mathrm{~m}$ above sea level. These were exceptions, since the majority of the species were composed of small to medium-sized beetles.

As a result of they were less likely to be caught in pitfall traps compared to savanna species. Spence and Niemela (1994) observed a similar tendency of large, heavybodied carabids of being caught in pitfall traps in relatively large numbers.

The inefficiency of pitfall traps compared to ground searching methods is reflected in by its low index of completeness of sampling (sampling intensity, i.e. individuals to species ratio). For spiders, Coddington et al. (1991) estimated that a specimens to species ratio of ten to one would be sufficient for the purpose of estimating species richness. If this figure is roughly true for carabid beetles (no similar estimate exists), then pitfall traps in the present study fall too short. It is clear from the above that pitfall traps did not produce optimal sampling. Ground searching data produced better results. This method is labour intensive, and therefore expensive. However this shortcoming can be alleviated by the use of untrained field helpers (Nyundo $2000 \mathrm{a}, \mathrm{b})$.

The conclusion from this study is that in the particular habitat where we sampled (rugged montane rain forest) pitfall trapping has no advantage over searching methods with respect to ease of operation, low cost or efficiency. However, despite its inefficiency, pitfall trapping cannot be left out of sampling protocols because the method sampled some species that were missed by ground searching methods. This is evident from the high complementality figures obtained in the present study.

\section{ACKNOWLEDGEMENTS}

The authors acknowledge financial and material assistance from the University of Dar es Salaam, the DANIDA-ENRECA Project, and Tanzania National Parks Authority. Our heartfelt thanks go to Mr. H. 
Mwasomola and H. Rashid, the field helpers during the sampling, and Drs. L. Sorensen and N. Scharff for assistance during the planning and execution of the project. Dr. M. Demeyer from the Royal Museum for Central Africa, Tervuren, Belgium, assisted with the identification.

\section{REFERENCES}

Adis J 1979 Problems of interpreting arthropod sampling with pitfall traps. Zoologischer Anzeiger, Jena 202: 177184.

Bremen T von and Terlutter H 1994 The estimation of carabids in a pasture by removal trapping. In: Desender, K. et al (eds.) Carabid beetles: Ecology and Evolution, 465-468.

Clark MS, Luna JM and Youngman RR 1995 Estimation of adult carabid absolute densities in a no-till corn field by removal sampling. Applied Soil Ecology 2:185-193.

Coddington JA, Griswold CE, Davila DS, Penaranda E and Larcher SF 1991 Designing and testing sampling protocols to estimate biodiversity in tropical ecosystems. In: Dudley EC (Ed.) The Unity of Evolutionary Biology: Proceedings of the Fourth International Congress of Systematic and Evolutionary Biology. Discorides Press, Portland, 44-60.

Colwell RK and Coddington JA 1994 Estimating terrestrial biodiversity through extrapolation. Phil. Trans. Roy. Soc. Lond. B 345: 101-118.

Davies J 2000 Beetles (Coleoptera) of Mkomazi. In: Coe M, McWilliam N, Stone G and Packer M (eds) Mkomazi: The ecology, biodiversity and conservation of a Tanzanian savanna.

Greenslade PJM 1968 Habitat and altitude distribution of Carabidae (Coleoptera) in Argyll, Scotland. Trans. Roy. Entomol. Soc. Lond. 120: 39-54.

Niemela J 1988 Habitat occupancy of carabid beetles on small islands and the adjacent Aland mainland, SW Finland. Annales Zoologici Fennici, 25:121-131.

Niemela J, Haila Y, Halme E, Pajunen T and Punttila P 1989 The annual activity cycle of carabid beetles in the southern Finnish taiga. Annales Zoologici Fennici 26: 35-41.

Niemela J, Tukia H and Halme E 1994 Patterns of carabid diversity in Finnish mature taiga. Annales Zoologici Fennici 31:123-129.

Nyundo BA 2002a Potential use of inexperienced field helpers in biodiversity surveys: the case of carabid beetle sampling. TAWIRI: Proceedings of the second annual scientific conference, Arusha, December -6, 2001: 179-192.

Nyundo BA 2002b The Diversity of Carabid Beetles (Coleoptera: Carabidae) in the Udzungwa Mountains National Park, Tanzania. PhD thesis, University of Dar es Salaam.

Refseth D 1980 Ecological analyses of carabid communities- potential use in biological classification for nature conservation. Biol. Cons. 17: 131-141.

Southwood TRE and Henderson PA 2000 Ecological Methods. Third Edition. Blackwell Science, Oxford.

Spence JR and Niemela JK 1994 Sampling carabid assemblages with pitfall traps: The madness and the method. The Canad. Entomol. 126: 881-894.

Vennila S and Rajagopal D 1999 Optimum sampling effort for study of tropical ground beetles (Carabidae: Coleoptera) using pitfall traps. Current Science 77: 281-283.

Zilihona, I.J.E. and Nummelin, M. (1999) A comparison of sampling techniques for insect biodiversity studies in remote areas of Tanzania: A case study of Udzungwa Mountains. Proceedings of the $4^{\text {th }}$ Scientific Conference of the Tanzania Entomological Association, 96-102. 


\section{APPENDIX}

List of species of carabid beetles in the six replicates

SPECIES

GROUND SEARCH PITFALL TRAPS

Replicate 1 (500m asl, wet season

Pentagonica montana

2

Metagonum sp.nov.

Eunostus sp.nov.

Abacetus sp.4

Pseudomegalonychus sp.nov.

Sphaerodes sp.

Thyreopterus sp.nov.2

Euripogena sp.nov.

Egadroma sp.1

1

0

Aulacorysus sp.

1

0

Euplines sp.nov.

2

92

2

1

7

6

12

Galeritiola procera ssp. procera

0

Platytarus congobelgicus

2

Thyreopterus limbatus

Egadroma sp.2

Abacetus sp. 2

2

$$
0
$$

0

Thyreopterus sp.nov.1

11

0

Morion sp.2

Parazuphium sp.

Dactyleuris sp.

Thyreopterus lugubris

Megalonychus sp.nov.2

Paracallistodes kirkii ssp.

eccoptomenoides

Metagonum bergeri

240

Crepidogaster sp.2

0

2

2

Procletus sp.

Replicate 2 (500m asl, dry season)

Pentagonica montana 
Pseudomegalonychus sp.nov.

Thyreopterus sp.nov.2

Egadroma sp.1

Aulacorysus sp.

Euplines sp.nov.

Abacetus sp.1

Megalonychus sp.nov.2

Galeritiola procera ssp. procera

Crepidogaster protuberata

Thyreopterinus sp.nov.2

Dichaetochilus sp.

Platytarus congobelgicus

Thyreopterus limbatus

Cymindoidea virgulifera

Paracallistodes kirkii ssp. eccoptomenoides

Egadroma sp. 2

Harpalpalus nigripes

$9 \quad 0$

Haplopeza violacea ssp.nov.

Abacetus sp.2

$1 \quad 0$

20

Harpalpalus sp.

Crepidogaster sp. 1

20

10

Thyreopterus sp.nov.1

Replicate 3 (1000m asl, wet season)

Pentagonica montana

Abacetus sp.4

$1 \quad 0$

Pseudomegalonychus sp.nov.

Sphaerodes sp.

150

Euripogena sp.nov.

Tyronia sp.1

3

3

Typhloscaris sp.

Megalonychus sp.nov.1

Craspedophorus sp.

$\begin{array}{ll}1 & 0 \\ 1 & 0 \\ 2 & 0\end{array}$




\begin{tabular}{|c|c|c|}
\hline \multicolumn{3}{|c|}{ Replicate 4 (1000m asl, dry season) } \\
\hline Pentagonica montana & 42 & 0 \\
\hline Abacetus sp.4 & 3 & 0 \\
\hline Pseudomegalonychus sp.nov. & 78 & 0 \\
\hline Disphaericus conradti & 1 & 0 \\
\hline Thyreopterus sp.nov.2 & 5 & 0 \\
\hline Euripogena sp.nov. & 4 & 0 \\
\hline Tyronia sp.1 & 1 & 0 \\
\hline Megalonychus sp.nov.1 & 2 & 0 \\
\hline Craspedophorus sp. & 4 & 0 \\
\hline Aulacorysus sp. & 3 & 0 \\
\hline Peliocypas pallidus & 2 & 0 \\
\hline Pentagonica elegans & 1 & 0 \\
\hline \multicolumn{3}{|c|}{ Replicate $5(1500 \mathrm{~m}$ asl, wet season) } \\
\hline Tachyphanes sp. & 201 & 0 \\
\hline Pentagonica montana & 88 & 0 \\
\hline Pseudomasoreus sp.nov. & 28 & 2 \\
\hline Metagonum sp.nov. & 71 & 19 \\
\hline Eunostus sp.nov. & 2 & 0 \\
\hline Abacetus sp.4 & 7 & 0 \\
\hline Metagonum sjostedti & 23 & 2 \\
\hline Chlaenius sp. & 3 & 2 \\
\hline Abacetus sp.5 & 6 & 0 \\
\hline Mamboicus sp. & 12 & 0 \\
\hline Orinochlaenius sp. & 1 & 0 \\
\hline Metagonum mboko & 24 & 0 \\
\hline Disphaericus conradti & 1 & 1 \\
\hline Thyreopterus sp.nov.2 & 4 & 0 \\
\hline Craspedophorus sp. & 1 & 0 \\
\hline Paraleleupidia uluguruana & 2 & 0 \\
\hline Tyronia sp.2 & 1 & 0 \\
\hline Abacetus sp.3 & 0 & 1 \\
\hline
\end{tabular}




\begin{tabular}{lcc}
\hline Replicate 6 (1500m asl, dry season) & & \\
\hline Tachyphanes sp. & 966 & 0 \\
Pentagonica montana & 83 & 0 \\
Pseudomasoreus sp.nov. & 37 & 1 \\
Metagonum sp.nov. & 42 & 19 \\
Abacetus sp.4 & 8 & 0 \\
Metagonum sjostedti & 70 & 0 \\
Abacetus sp.5 & 3 & 0 \\
Pseudomegalonychus sp.nov. & 1 & 0 \\
Sphaerodes sp. & 1 & 0 \\
Thyreopterus sp.nov.2 & 9 & 0 \\
Paraleleupidia uluguruana & 7 & 0 \\
Tyronia sp. 2 & 1 & 0 \\
Abacetus sp. 1 & 1 & 0 \\
Peliocypas pallidus & 3 & 0 \\
Diatypus sp. & 1 & 0 \\
Disphaericus conradti & 0 & 1 \\
Tyronia sp. 1 & 0 & $\mathbf{7 2}$ \\
TOTAL & $\mathbf{3 0 2 5}$ &
\end{tabular}

